Manzano Águila, José Daniel.

Profesor de carrera de tiempo completo de la Facultad de Artes y Diseño de la UNAM.

\title{
La investigación-producción en las artes y el diseño.
}

\author{
TIPO DE TRABAJO
}

Comunicación.

PALABRAS CLAVE

Investigación, producción, tesis, arte, diseño.

KEY WORDS

Research, production, thesis, art, design.

\section{RESUMEN}

Por lo regular cuando hablamos de investigación pensamos en temas culturales o de educación en el campo de las ciencias duras o las sociales, inclusive en las humanidades, pero difícilmente en el arte (plástica, visual, música, teatro, cine, poesía, etc.) o el diseño (gráfico y la comunicación visual), y es que al diseño industrial ligado a la arquitectura le gusta bandear entre la ciencia y las artes. La investigación inclusive abarca los estudios en historia del arte, estética y filosofía del arte, disciplinas cuyo sustento y materia de discusión, análisis y crítica es la producción artística o el diseño. ¿Qué pasa con los procesos creativos mediante los cuales se obtiene en el campo del arte un objeto o producto determinado?; ¿qué motiva a una persona a producir ciertos objetos y cuáles son los pasos (para otros, métodos) y las herramientas para ello?; ¿qué pasa en el arte y el diseño con la observación, el planteamiento del problema, la experimentación, la realización final y los resultados?

¿Es posible diferenciar la investigación en artes y diseño de la que se da en la academia sobre esos mismos temas?, ¿de qué modo podríamos vincular la investigación y la producción para construir un nuevo concepto que englobe ambas actividades en la docencia y en el campo profesional? Para que las aportaciones de dichos campos a la sociedad sean visibles, es necesario abrir otros horizontes y líneas de reflexión en los que se analice la práctica artística, el diseño y sus procesos creativos.

\section{ABSTRACT}

When we talk about research, usually daily, or academic circumstances force us to think for a cultural or educational issue in the various fields of the hard sciences or social sciences or even in the humanities, but hardly in art - either plastic, visual, music, theater, film, poetry, etc., or I mean the graphic design and communication visually, because industrial design linked to architecture, he likes bandear between science and the arts. You can even speak of research and include studies in art history, aesthetics and philosophy of art, although these disciplines livelihoods and matter in which base their discussion, analysis, critique, is the artistic design or production. And really going on with the real creative process by which an object or product in the field of art is obtained; that is what motivates a person to produce certain objects and what steps -to other methods- and the instruments or tools to do so. What about watching the approach of a problem, experimentation, the final implementation and results. It is possible to differentiate research in arts and design, and which is given on the arts and design at the academic level, and that way we link the concepts of production research, to conform as a new concept in teaching. You need to open new horizons and lines of research that allow research in art and design are geared to reflect on practice and their creative processes, to really have the contribution to society is observed. 


\section{CONTENIDO}

Por lo regular cuando hablamos de investigación pensamos en temas culturales o de educación en el campo de las ciencias duras o las sociales, inclusive en las humanidades, pero difícilmente en el arte (plástica, visual, música, teatro, cine, poesía, etc.) o el diseño (gráfico y la comunicación visual), y es que al diseño industrial ligado a la arquitectura le gusta bandear entre la ciencia y las artes.

Se reconoce el proceso de investigación inclusive en estudios de historia del arte, estética y filosofía del arte, disciplinas cuyo sustento y materia de discusión, análisis y crítica es la producción artística o el diseño, cuyos objetos están llenos de subjetividad, caprichos, extravagancias o inspiración proveniente de estados alterados, pero que al ser tocados por los especialistas se convierten en objetos de arte, materia de estudio y hasta motivo de teorías del arte y filosóficas. Hay investigaciones profusamente fundadas en las obras de Sócrates y Platón, Gaston Bachelard, Martin Heidegger, Jacques Lacan, Michel Foucault, Walter Benjamin, Friedrich Hegel, Immanuel Kant, Karl Marx, Eco, Deleuze, Guattari y Arnheim; si se trata de lenguaje, es obligado incluir a Saussure, Pierce, Derrida y muchos otros que escriben sobre la imagen y la producción de objetos artísticos.

¿Qué pasa con los procesos creativos mediante los cuales se obtiene un objeto o producto determinado dentro del campo del arte?; ¿qué motiva a una persona a producir ciertos objetos y cuáles son los pasos - para otros métodos- e instrumentos para realizarlos? ¿Qué pasa con la observación, el planteamiento de un problema, la experimentación, la realización final y los resultados? Para realizar un proceso (creativo) y obtener un resultado determinado, un científico parte de la observación y la experimentación. En las ciencias sociales y las humanidades también hay observación, aunque poca experimentación (que se sustituye por la interpretación de los hechos y los resultados). ¿Cuál es entonces la diferencia entre unas y otras disciplinas? ¿En qué varían los resultados? (lo más seguro, en el lenguaje). Las áreas más cercanas a los procesos de investigación son la ciencia y el arte. El lenguaje las diferencia: en una es críptico y especializado, dirigido a un número de personas determinado, mientras que en el otro es más universal, aunque no todos se identifiquen con él.

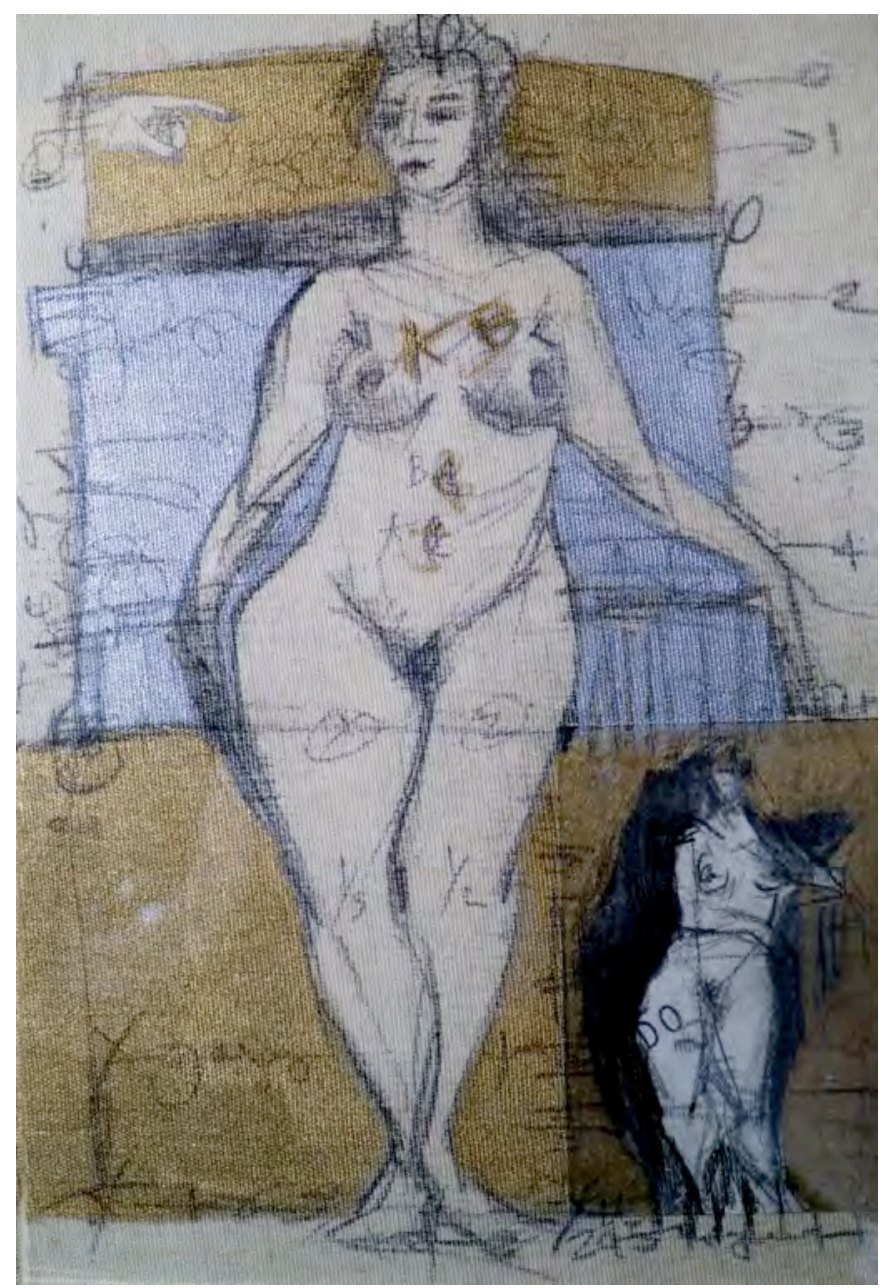

Dibujo de Daniel Manzano, 2015. 
Se piensa que el artista (o diseñador) produce pensando en la belleza, la fealdad, la imagen, la teoría y filosofía del arte, la estética, pero quien lo piense así comete un error. Pensar de ese modo equivaldría a decir que cada experimento en la ciencia está pensado y justificado en los modelos científicos de hace cincuenta años, cuando el avance tecnológico aún no reducía el tiempo experimental y de investigación.

Los que justifican y fundamentan sus investigaciones son los teóricos (de cualquier disciplina) que trabajan con documentos o hechos que involucran a los seres humanos (como protagonistas, actores o autores materiales de los hechos). De ahí que constantemente utilicen teorías que contribuyen a aclarar o justificar los acontecimientos (históricos o no, aunque en este momento ya todo es historia).

¿Cómo justifican sus tesis los arquitectos, ingenieros, físicos o químicos, veterinarios o médicos? ¿Qué fundamentos teóricos o filosóficos respaldan la construcción de un puente o un edificio? ¿Qué marco teórico o filosófico utiliza un veterinario, un químico o un físico para justificar un experimento?

¿Por qué el productor de artes y diseño debe justificar teórica o filosóficamente su producción, independientemente de que sus estudios y conocimientos sobre historia, teoría y filosofía del arte y la imagen sean amplios? Todo indica que la producción artística no es vista como resultado de una investigación o de un proceso creativo que en sí mismo requiere métodos y herramientas propios.

Se cree erróneamente que cualquiera puede crear un objeto artístico (independientemente de las banalidades en que se ha caído, donde una caja de zapatos, unos balones desinflados o unas cobijas manchadas con sangre de cerdo se convierten en objetos artísticos gracias a los grandes capitales de las galería y a sus intereses no muy claros). El arte necesita conocimientos diversos (teóricos y prácticos) que requieren métodos, técnicas (tradicionales o nuevas) y tecnologías, y ello no excluye la posibilidad de que un artista o diseñador reflexione teóricamente sobre su producción o la de otros Por el momento no tenemos pero es muy buena idea, así es que por lo pronto lo dejamos así.

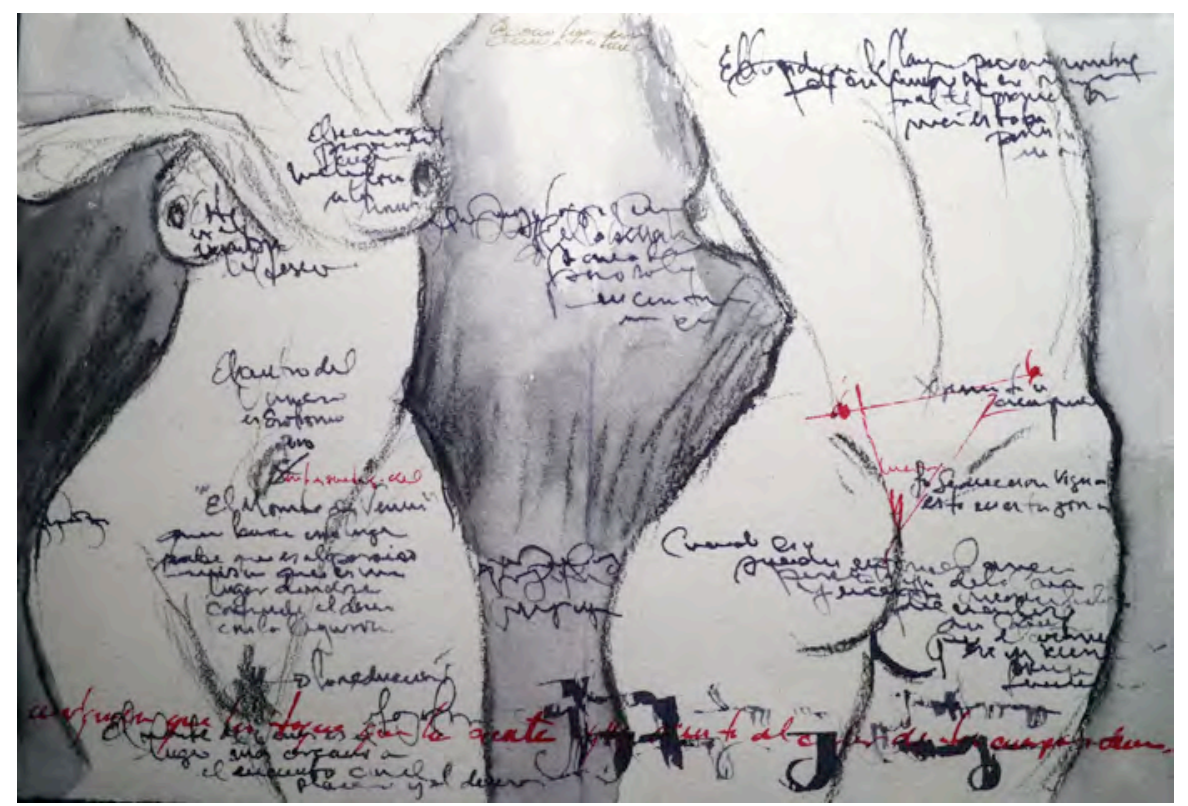

Dibujo de Daniel Manzano, 2015.

Teoría y práctica están íntimamente ligadas, así como las partes del concepto investigación-producción no pueden separarse. Lo que el artista o diseñador debe fundamentar teóricamente es su producción a partir de sus propios procesos, métodos y técnicas creativas. Por ello una obra original realizada con técnicas y procedimientos ortodoxos no se puede repetir (no es lo mismo que reproducir) con fórmulas establecidas; de ahí proviene su originalidad y su valor (de uso y de cambio). En cambio, las obras realizadas con las nuevas tecnologías pueden repetirse e incluso reproducirse de manera infinita, así como ser admiradas por miles de personas en todo el mundo por medio de las redes sociales digitales y la virtualidad. Ahora es posible crear nuestra propia galería o museo virtual, incluso interactivo, con las imágenes fijas o en movimiento, y traerlo en el teléfono celular o en cualquier otro dispositivo para disfrutarlo cuando y donde se desee.

La reproducción de ese tipo es legal; no se comercializa, se baja de la nube, es gratuita e incluso alterable: me la puedo apropiar, es mía para mi uso y disfrute, es mi fuente de conocimiento. En esa perspectiva surge una alternativa: la apropiación como propuesta plástica posmoderna o contemporánea basada en las nuevas tecnologías de la información, y la comunicación y sus múltiples programas herramientas, métodos, materiales, técnicas, procedimientos, etcétera. 
¿Qué es lo que integra una tesis determinada?, ¿una introducción, un marco de referencia (con tres submarcos: histórico, teórico y conceptual), la tesis, las conclusiones y un aparato critico que la sustente? Vale preguntarse cuántas tesis sobre temas parecidos cuentan con un marco de referencia similar, sobre todo en occidente, en donde compartimos las mismas referencias teóricas (señaladas arriba). ¿Dónde está la originalidad de esas investigaciones? Sin embargo, en el campo del arte (o del diseño) cada obra es distinta y todas provienen de un largo proceso de investigación y experimentación, de un dominio del espacio y los elementos estéticos.

¿Qué pasa con los procesos creativos en las artes y el diseño?, ¿cómo se registran los métodos y técnicas de producción y cuál es su valor en el desarrollo de la investigación-producción? En general, esos procesos se registran en apuntes, bitácoras, libretas de trabajo, registros fotográficos, dibujos, bocetos o todo lo que sirva para registrar el desarrollo de una obra determinada. Ese proceso es el que permitirá a otras disciplinas afines elaborar teorías en el campo de la producción artística.

Concluiremos preguntándonos de dónde proviene la idea de que una tesis de cualquier grado en el campo de las artes y el diseño debe ser teórica o eminentemente teórica: ¿por qué debe ser así si el trabajo de esos profesionales es producir objetos artísticos?, ¿por qué en este campo la teoría no podría venir después de la producción?, ¿que impide producir primero, si conocemos la materia y dominamos la teoría, los métodos y las técnicas? En el arte y el diseño, el producto es el resultado de la investigación, que incluye un proceso creativo con referencias prácticas y teóricas que validan la investigación-producción.

Ahora se abre una nueva línea de investigación que diferencia entre el que escribe los procesos creativos sobre lo que realiza y el que al escribir especula sobre ese mismo producto pero sin haberlo fabricado.

\section{FUENTES REFERENCIALES}

ARNHEIM, Rudolf, Consideraciones sobre la educación artística, Paidós, Barcelona, 1993.

CARRION, Ulises, El arte nuevo de hacer libros: ARCHIVOS CARRION I, CONACULTA, Tumbona Ediciones, México, 2012.

ECO, Umberto, Cómo se hace una tesis, Gedisa, España, 1992.

GUITTON, Jean, El trabajo intelectual, RIALP, Madrid, 1999.

MARINA, José Antonio, Teoría de la inteligencia creadora, 9a. ed., Anagrama, Barcelona, 1998.

MUNARI, Bruno, ¿Cómo nacen los objetos?, Gustavo Gili, Barcelona, 1983. 